\title{
Impact of switching of the electrical harvesting interface on microbial fuel cell losses
}

\author{
Armande Capitaine ${ }^{1,2}$, Gael Pillonnet ${ }^{1}$, Thibaut Chailloux ${ }^{1}$, Adrien Morel $^{1}$ and Bruno Allard ${ }^{2}$ \\ ${ }^{1}$ Univ. Grenoble Alpes, CEA, LETI, DACLE, LGECA, F-38000 Grenoble, France \\ ${ }^{2}$ Univ. de Lyon, INSA Lyon, Ampère, UMR CNRS 5005, F-69621 Villeurbanne, France
}

\begin{abstract}
Microbial fuel cells (MFCs) are sources harvesting energy from organic matters and showing great promise in powering environmental sensors. Because of the low power and voltage issues $\left(100 \mu \mathrm{W}\right.$ at $0.3 \mathrm{~V}$ for $20 \mathrm{~cm}^{2}$ electrodes), an electrical interface is required to extract the maximum power delivered by the MFC and boost the output voltage. However the switching operation of most converters induces a pulsed sinking current which may cause additional dynamic losses inside the MFC. Following a previous study on a flyback converter in discontinuous conduction mode, this paper analyzes the effect of switching of the converter on the MFC internal losses. A dynamic model of the MFC is deduced from an impedance spectroscopy characterization: it reveals a double $\mathrm{RC}$ behavior, one with a time constant of $10 \mathrm{~s}$ of $\mathrm{s}$, the other one of 100s of $\mu \mathrm{s}$. Then in the frequency-domain, the MFC dynamic losses, induced by a previously optimized flyback, are calculated: they represent $50 \%$ of the maximum power that can be extracted from the MFC. Eventually in order to reduce these losses, we study the impact of three flyback parameters (primary inductance, duty cycle and decoupling capacitance). Adding a capacitance of $10 \mu \mathrm{F}$ at the converter input, the MFC dynamic losses become negligible.
\end{abstract}

Keywords-microbial fuel cell; flyback converter; energy harvesting; dynamic electrical model; impedance spectroscopy

\section{INTRODUCTION}

Discovered in the last decades, microbial fuel cells (MFCs) are promising sources for scavenging energy from organic substrates (e.g. compost, sediment, wastewater...) by converting chemical energy into electricity thanks to catalysis properties of electro-active bacteria [1]. They can be seen as an attractive alternative to polluting batteries to power sensors in hardly reachable areas (e.g. seafloors). Regarding the low voltage and low power the MFCs generate $\left(100 \mu \mathrm{W}\right.$ at $0.3 \mathrm{~V}$ for $20 \mathrm{~cm}^{2}$ electrodes [2]), an electrical interface, i.e. a DC/DC converter, is required to extract the maximum power, $\mathrm{P}_{\mathrm{MPP}}$, from the $\mathrm{MFC}$ and boost the voltage to the level required by the sensor. However these converters, because of their inherent switching operation, impose a pulsed sinking current which may cause additional losses inside the MFC, on top of the well-known losses due to the DC current (static losses). These additional losses due to AC currents are called MFC dynamic losses. The paper follows a previous work $[3,4]$ where the MFC interface is a flyback converter in discontinuous conduction mode (DCM) extracting energy from a benthic MFC with $20 \mathrm{~cm}^{2}$ electrodes and a maximum power of $90 \mu \mathrm{W}$. So far only the MFC static losses have been considered in literature. The paper studies the MFC additional dynamic losses induced by the switching operation of the flyback converter.
First a dynamic model of the MFC will be determined from experimental data obtained with electrochemical impedance spectroscopy (EIS) [5]. Then we will study the impact of the dynamic current imposed by the converter on the MFC dynamic losses. After developing a calculation method of the MFC dynamic losses, we will analyze the influence of three converter parameters (primary inductance, duty cycle, input capacitance) on these losses for minimization, i.e. avoid inefficient consumption of the organic substrate.

\section{ELECTRICAL MODELING OF MFC}

\section{A. Static behavior}

A typical way to model the MFC static behavior is shown in Fig. 1. The polarization curve is comparable to a straight line corresponding to a Thevenin circuit. Our lab-scale MFC generates $\mathrm{P}_{\mathrm{MPP}}=90 \mu \mathrm{W}$ at the maximum power point (MPP) and corresponds to an open-circuit voltage source $\mathrm{V}_{\mathrm{OC}}$ of $0.6 \mathrm{~V}$ and a series resistance $\mathrm{R}_{\mathrm{DC}}$ of $1 \mathrm{k} \Omega$ [2]. However this model does not reflect the dynamic behavior of the MFC when an AC stimuli is applied.

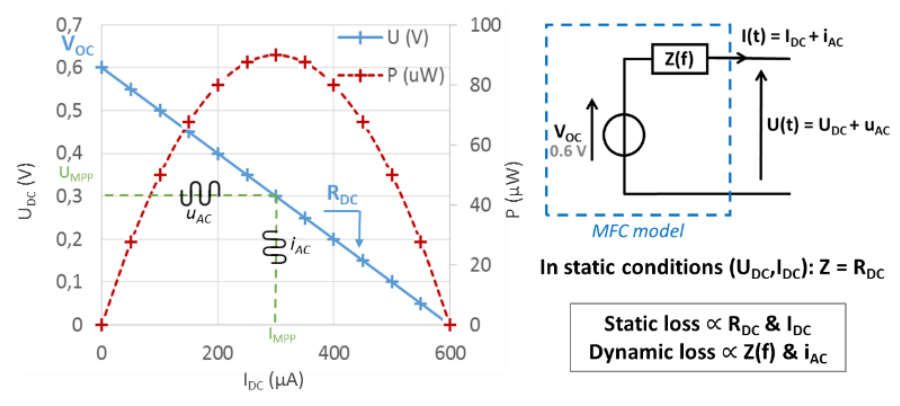

Fig. 1. Static characteristic of the MFC associated to the MFC electrical model

\section{B. Dynamic characterization}

The EIS method is adopted in order to to appreciate the MFC dynamic behavior at different $\mathrm{DC}$ operating point $\left(\mathrm{U}_{\mathrm{DC}}, \mathrm{I}_{\mathrm{DC}}\right)$. This method consists in adding a sinusoidal perturbation $\mathrm{u}_{\mathrm{AC}}$ with variable frequency $f$ to the polarization voltage $U_{D C}$ (as schematized in Fig. 1). The amplitude of $u_{A C}$ is fixed to $50 \mathrm{mV}$ so that the MFC can accurately be apprehended as a linear system. The resulting current, expressed as the sum of the static current $\mathrm{I}_{\mathrm{DC}}$ and a sinusoidal perturbation $\mathrm{i}_{\mathrm{AC}}$, is then measured. From these measurements, we can deduce an MFC equivalent dynamic impedance $\mathrm{Z}(\mathrm{f})$ at different frequency $\mathrm{f}$ for a specific DC point $\left(\mathrm{U}_{\mathrm{DC}}, \mathrm{I}_{\mathrm{DC}}\right)$. Its amplitude $|\mathrm{Z}|$ and phase $\varphi$, when working at $\mathrm{MPP}\left(\mathrm{U}_{\mathrm{DC}}=0.3 \mathrm{~V}\right)$, are represented in Fig. 2. Similar AC characteristic is obtained for other polarization voltages. Weassume the MFC dynamic behavior is independent of the 
polarization point. Moreover the frequency range is large since some physical aspects characterized at low frequency (e.g. mHz) may have a significant impact even when using a $\mathrm{kHz}$ switching frequency converter.
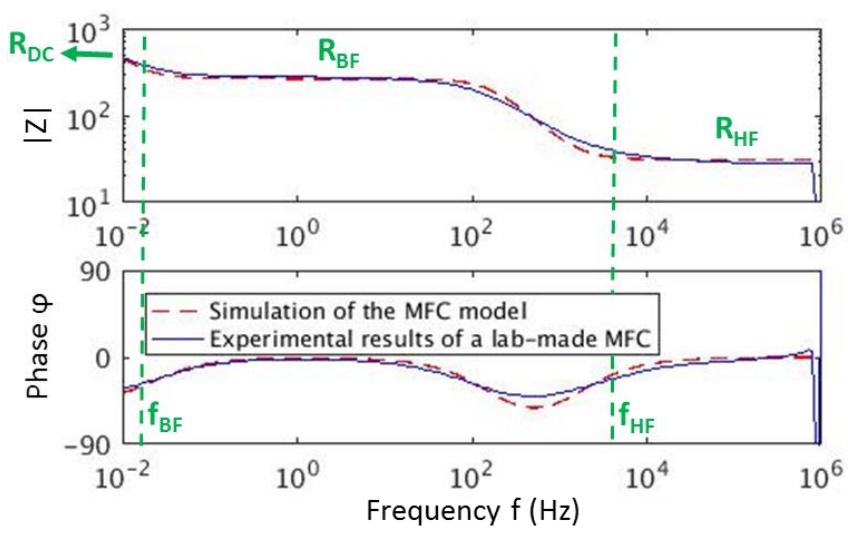

Fig. 2. Amplitude and phase of the MFC dynamic impedance obtained experimentally with the impedance spectroscopy method (blue solid line) and of the deduced dynamic model of the MFC (red dashed line).

\section{Dynamic electrical model}

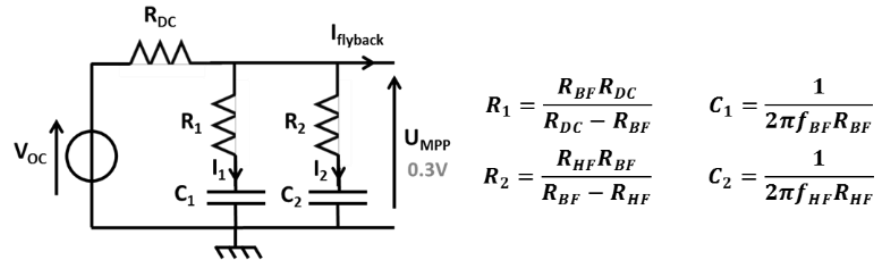

Fig. 3. Dynamic model of the MFC

The dynamic electrical circuit deduced from the previous characterization is represented in Fig. 3. To the static model is added two parallel $\mathrm{RC}$ branches, one $\left(\mathrm{R}_{1} \mathrm{C}_{1}\right)$ being associated to the low cut-off frequency $f_{B F}$, the other $\left(R_{2} C_{2}\right)$ to the higher one $\mathrm{f}_{\mathrm{HF}}$ (Fig. 2). The circuit components are calculated using equations in Fig. 3 in which $\left\{\mathrm{R}_{\mathrm{BF}}, \mathrm{R}_{\mathrm{HF}}, \mathrm{f}_{\mathrm{BF}}, \mathrm{f}_{\mathrm{HF}}\right\}$ are evaluated from $\mathrm{AC}$ measurements (Fig. 2). $\mathrm{R}_{\mathrm{DC}}$ is not readable in Fig. 2 as extended $\mathrm{AC}$ measurements at lower frequencies is very time consuming. $\mathrm{R}_{\mathrm{DC}}$ is thus deduced from a previous static characterization (Fig. 1). The results are listed in Table I..It shows an accurate fit with the experimental data (Fig. 2).

TABLE I. VALUES OF THE DYNAMIC MODEL COMPONENTS

\begin{tabular}{|c|c|c|c|c|}
\hline $\mathrm{R}_{\mathrm{DC}}$ & $\mathrm{R}_{1}$ & $\mathrm{C}_{1}$ & $\mathrm{R}_{2}$ & $\mathrm{C}_{2}$ \\
\hline $1 \mathrm{k} \Omega$ & $347 \Omega$ & $30 \mathrm{mF}$ & $35 \Omega$ & $3 \mu \mathrm{F}$ \\
\hline
\end{tabular}

The first branch $\mathrm{R}_{1} \mathrm{C}_{1}$ has a time constant of the order of $10 \mathrm{~s}$ of seconds and can be associated to the transport mechanisms of the organic matter to the electrodes [6]. Whereas the second branch $\mathrm{R}_{2} \mathrm{C}_{2}$, having a time constant of the order of $100 \mathrm{~s}$ of microseconds may be due to the double layer electrical behavior at the electrodes' surface [6]. Therefore the MFC presents two dynamic resistances $R_{1}$ and $R_{2}$ that may engender additional intrinsic losses.

\section{INFLUENCE OF THE HARVESTING INTERFACE ON THE MFC DYNAMIC LOSSES}

\section{A. Harvesting interface}

Using the previous work presented in [3], the flyback in DCM is chosen as an harvesting interface mainly for its isolation capability. As explained in [3], to work at the DC-MPP and extract the maximum DC energy from the MFC, the flyback input impedance $\mathrm{R}_{\mathrm{IN}}$ has to meet the following constraints:

$$
R_{I N}=\frac{2 L_{1} f_{S W}}{D^{2}}=R_{D C}
$$

$\mathrm{L}_{1}$ is the primary inductance, $\mathrm{D}$ the duty cycle and $\mathrm{f}_{\mathrm{sw}}$ the switching frequency of the flyback. This means the three parameters $\left\{\mathrm{L}_{1}, \mathrm{D}, \mathrm{f}_{\mathrm{sw}}\right\}$ are linked. In [4] it was chosen to work with a coreless transformer to avoid converter losses due to saturation and hysteresis and thus maximize the converter efficiency. The same experimental set-up $\left\{\mathrm{L}_{1}, \mathrm{D}, \mathrm{f}_{\mathrm{sw}}\right\}=\{583 \mu \mathrm{H}, 0.07,4.23 \mathrm{kHz}\}$ will be used in the following study to evaluate the additionnal $A C$ losses due to $\mathrm{R}_{1}$ and $\mathrm{R}_{2}$.

\section{B. Calculation of the MFC dynamic losses}

Transient simulations may be very time consuming regarding the 10 s of second time constant at stake in the MFC dynamic model compared to $\mathrm{kHz}$ flyback switching operation and so the time needed to reach steady-state operation. An analytical frequency approach based on the Fourier decomposition is thus preferred. For the sake of simplification, the flyback input current, called $\mathrm{I}_{\text {flyback }}$ in Fig. 4 , is considered of constant at the flyback input and independent of MFC energy production. In frequency domain, we calculate the Fourier series of currents $I_{1}$ and $I_{2}$ in Fig. 3 using the respective transfer functions regarding $\mathrm{I}_{\text {flyback }}$ and the Fourier series of $\mathrm{I}_{\text {flyback. }}$. Again in the time-domain, the losses $\mathrm{P}_{1}$ and $\mathrm{P}_{2}$ induced respectively by the branch $\mathrm{R}_{1} \mathrm{C}_{1}$ and $\mathrm{R}_{2} \mathrm{C}_{2}$ are deduced. The method is summarized for $\mathrm{P}_{1}$ in Fig. 4.
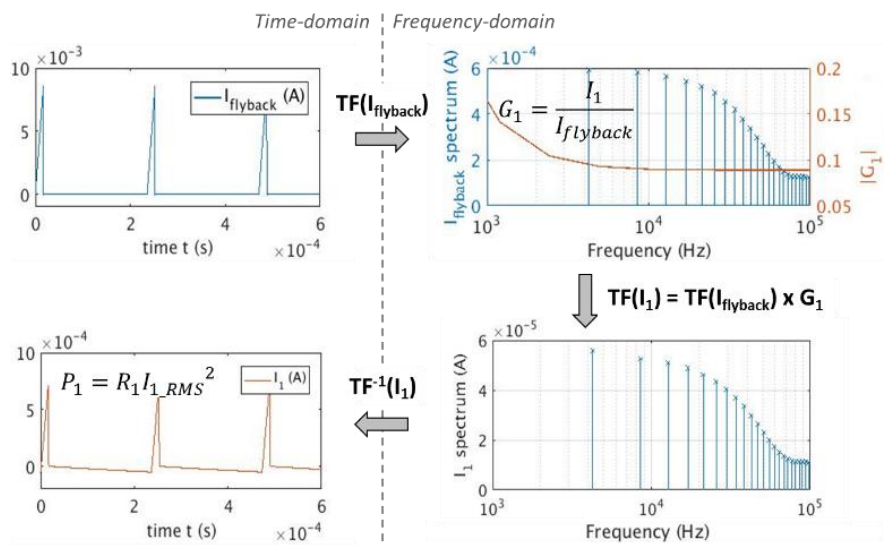

Fig. 4. Method of the dynamic losses calculation, example of $\mathrm{P}_{1}$ calculation

\section{Results}

Following this calculation process, in the chosen conditions $\left\{\mathrm{L}_{1}, \mathrm{D}, \mathrm{f}_{\mathrm{sw}}\right\}=\{583 \mu \mathrm{H}, 0.07,4.23 \mathrm{kHz}\}, \mathrm{P}_{1}$ is equal to $4.4 \mu \mathrm{W}$ and $\mathrm{P}_{2}$ to $42.9 \mu \mathrm{W}$, representing respectively $5 \%$ and $48 \%$ of the extracted DC power $\mathrm{P}_{\mathrm{MPP}}$ (equal to $90 \mu \mathrm{W}$ ). Therefore the dynamic part of the MFC undergoes non-negligible losses compared to the $90 \mu \mathrm{W}$ corresponding to the $\mathrm{DC}$ losses due $\mathrm{R}_{\mathrm{DC}}$. 
This means a power equivalent to $53 \%$ of the one usefully delivered to the converter is lost inside the MFC, contributing to a useless depletion of the organic matter resources. In order to reduce these losses, we will vary different flyback parameters, e.g. $\mathrm{L}_{1}$ and $\mathrm{D}$, to change the frequency spectrum of the currents $I_{1}$ and $I_{2}$ and thus the energy dissipation in respectively in $R_{1}$ and $\mathrm{R}_{2}$.

Influence of $\mathbf{L}_{1}$ : fixing $\mathrm{D}$ to $0.07, \mathrm{P}_{1}$ and $\mathrm{P}_{2}$ are calculated for $\mathrm{L}_{1}$ varying from $2 \mu \mathrm{F}$ to $200 \mathrm{mF}$. In order to respect (1) and work at the DC-MPP, $\mathrm{f}_{\mathrm{sw}}$ is constantly adapted (from $1.23 \mathrm{MHz}$ to $12.3 \mathrm{~Hz}$ ). The results are shown in Fig. 5. When increasing $L_{1}$, i.e. decreasing $f_{s w}, I_{1}$ increases $\left(\left|G_{1}\right|\right.$ increases in the lower frequencies, Fig. 4 ) while $I_{2}$ decreases. Regarding the high value of $R_{1}$ compared to $R_{2}$, the increase in $P_{1}$ is more significant than the decrease in $\mathrm{P}_{2}$, hence the total dynamic losses explode, especially for $L_{1}>100 \mathrm{mH}$. For lower values, $L_{1}$ variations have no impact on the dynamic losses which remain equal to $52.6 \%$ of $\mathrm{P}_{\mathrm{MPP}}$. Therefore considering our previous working conditions $\left(\mathrm{L}_{1}=583 \mu \mathrm{H}\right)$, no minimization of the dynamic losses can be made by varying $L_{1}$.

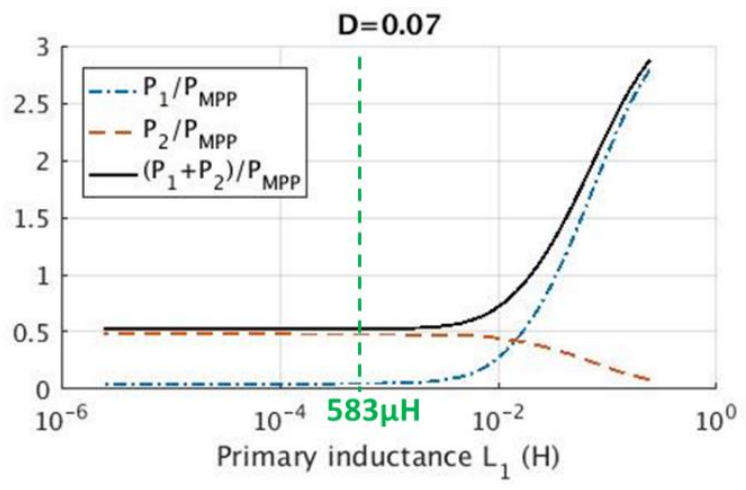

Fig. 5. Influence of $\mathrm{L}_{1}$ choice on the MFC dynamic losses $(\mathrm{D}=0.07)$

Influence of D: $\mathrm{L}_{1}$ is fixed to $583 \mu \mathrm{H}$ and $\mathrm{D}$ varies from 0 to 1 while adapting $\mathrm{f}_{\mathrm{sw}}$ according to (1) as it was done in the previous case. The results are shown in Fig. 6. When decreasing $D$, i.e. decreasing $\mathrm{f}_{\mathrm{sw}}$, the dynamic losses increase exponentially. These losses are particularly important when working with D lower than 0.2 . Then working with a $\mathrm{D}$ higher than 0.5 , i.e. $\mathrm{f}_{\mathrm{sw}}$ higher than $214 \mathrm{kHz}$, ensures negligible dynamic losses. However [3] has shown that such an increase in $f_{\mathrm{sw}}$ causes critical switching losses inside the flyback and thus drastically reduces its conversion efficiency. Therefore another way to reduce $\mathrm{P}_{1}$ and $\mathrm{P}_{2}$ without impacting on the conversion efficiency is needed.

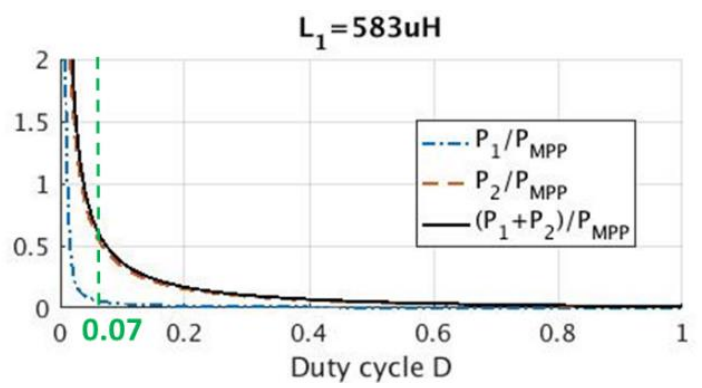

Fig. 6. Influence of D choice on the MFC dynamic losses $\left(\mathrm{L}_{1}=583 \mu \mathrm{H}\right)$
Influence of $\mathbf{C}_{\mathbf{I N}}$ : using the initial parameters given in section III.A, a capacitance is added at the input of the flyback converter. The results are displayed in Fig. 7. We observe that the inclusion of this capacitance decreases the MFC dynamic losses. This decrease becomes significant for $\mathrm{C}_{\text {IN }}$ larger than few $\mu \mathrm{F}$ for which the dynamic losses represent less than $1 \%$ of the extracted power $\mathrm{P}_{\mathrm{MPP}}$. With $\mathrm{C}_{\mathrm{IN}}=10 \mu \mathrm{F}$ (which represents a negligible extra surface on a PCB), these losses are equal to $0.1 \%$ of $\mathrm{P}_{\mathrm{MPP}}$ and may be neglected. Indeed all the AC current is flows in $\mathrm{C}_{\mathrm{IN}}$, causing no loss as ESR is neglected.

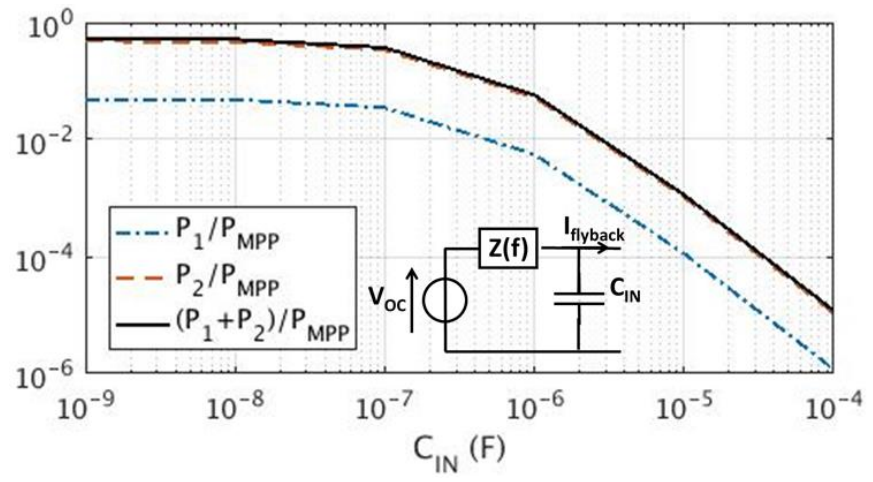

Fig. 7. Influence of a capacitance $\mathrm{C}_{\mathrm{IN}}$ at the input of the flyback on the MFC dynamic losses $(\{\mathrm{L} 1, \mathrm{D}, \mathrm{fsw}\}=\{583 \mu \mathrm{H}, 0.07,4.23 \mathrm{kHz}\})$

\section{CONCLUSION}

The paper analyzes the influence of the flyback converter in DCM on the intrinsic losses of an MFC. Because of the switching behavior, the converter imposes dynamic currents to the MFC which may induce dynamic losses inside the MFC. First a dynamic model composed of two parallel RC branches associated to time constants of the order of $100 \mathrm{~s}$ of $\mu \mathrm{s}$ and $10 \mathrm{~s}$ of $s$ was deduced from measurements obtained with EIS. Second we analyzed the influence of the flyback design (always working at MPP) on the losses induced by these two dynamic branches. Varying $\mathrm{L}_{1}$ offers no possible optimization, while increasing D may significantly reduce the dynamic losses. However increasing D means increasing $f$ which drastically reduces the flyback efficiency. Eventually we show that inserting a decoupling capacitance larger than $10 \mu \mathrm{F}$ at the input of the converter reduces the MFC dynamic losses from $52.6 \%$ to $0.1 \%$ of the extracted power $\mathrm{P}_{\mathrm{MPP}}$.

\section{REFERENCES}

[1] B.E. Logan et al., Microbial fuel cells: methodology and technology, Environ. Sci. Technol., 40 (2006) 5181-5192.

[2] T. Chailloux et al., Autonomous sensor node powered by $\mathrm{cm}$-scale benthic microbial fuel cell and low-cost and off-the-shelf components, Energy Harvesting and Systems, 3 (2016) 205-212.

[3] A. Capitaine et al., Loss analysis of flyback in discontinuous conduction mode for sub-mW harvesting systems, IEEE Proceedings of new Circuits and Systems Conference (NEWCAS), 2016.

[4] Y. Wanderoild et al., $100 \mu \mathrm{W}$ coreless flyback converter for microbial fuel cells energy harvesting, New generation of circuits and systems (NGCAS), 2017, in press.

[5] X. Z. Yuan et al., Electrochemical impedance spectroscopy in PEM fuel cells, Springer, 2010

[6] A. Dhirde et al., Equivalent electric circuit modeling and performance analysis of a PEM fuel cell stack using impedance spectroscopy, IEEE Transactions on energy conversion, 25 (2010) 778-786. 